\section{Non-earth science}

Planetary Geology. By Nicholas M. Short. Pp. xv+361. (Prentice-Hall : Englewood Cliffs, New Jersey, April 1975.) $\$ 17.95$.

THE content of this book is both narrower and wider than the title Planetary Geology would imply. The only extraterrestrial body to have been visited by man, extensively sampled and studied with a variety of on-site instruments is, of course, the Moon; and so it is hardly surprising that over $50 \%$ of the book should be devoted to lunar studies. Making allowances for the general introduction, the summing up and a chapter each on meteorites, the origin of planets and general aspects of the Solar System, only $15 \%$ of the book remains for "Mars, Venus, and the planets beyond"-a fair reflection of the present state of knowledge.

On the other hand, the term 'geology' is plainly inadequate, even for the seven chapters which summarise our physico-geological knowledge of the Moon. Dr Short is an employee of NASA and has used the perspective this gives him to write a book which sets the science firmly against the operational and methodological background

\section{IAEA Publications}

\section{Thermodynamics of Nuclear Materials I974}

Volume 1

Proceedings of a Symposium, Vienna, 21-25 October 1974

$£ 12(£ 12.37)$

\section{Formation of Uranium Ore Deposits}

Proceedings of a Symposium, Athens, 6-10 May 1974

$£ 16.40(£ 16.86)$

\section{Atoms, Molecules and Lasers}

Lectures presented at the International Winter College, Trieste, 17 January-10 April 1973, organized by the International Centre for Theoretical Physics, Trieste.

$£ 16(£ 16.46)$

Prices in brackets include postage

Post your orders to HMSO, PO Box 569 , London SE1 9NH. Government publications and those of certain International

Organisations can be obtained from HMSO Bookshops/Agents or booksellers. of lunar exploration. This "inquiryand problem-oriented" approach gives the book a distinctive flavour which I found a welcome change from the artificial world of the average text. The inclusion of wider contextual details may lead to some cavilling among academic purists, but the effect is surely to enhance rather than detract from the purely scientific story.

In a fast-moving field such as this, rapid dating of material is an obvious and serious problem. This book takes account of work caried out by to July 1974 (a remarkable achievement under present circumstances), which makes it the most up-to-date and comprehensive text on the subject now available. It would be a pity if it were allowed to age, for it forms an excellent foundation upon which to build later results; and I hope that Dr Short will be granted both the facilities and inspiration for frequent updating. Not that he is a stranger to revision. The first draft of this text was used and evaluated by students and then extensively rewritten in the light of the criticism and suggestions received. This is a procedure which many other authors could well adopt with benefit to themselves and advantage to their suffering readers.

Peter J. Smith

\section{Chromosomin}

\section{re-emerges}

\section{from limbo}

Acidic Proteins of the Nucleus. (Cell Biology: A Series of Monographs.) Edited by Ivan L. Cameron and James R. Jeter. (Academic: New York and London, December 1974.) \$28.50; $£ 13.70$.

Chromosomin was described by Edgar and Ellen Stedman about 35 years ago as one of the three major components of chromosomes, the other two being nucleic acids and histones. They postulated that it could have a structural role in the chromosome whereas the histones were gene regulators. Partly because of this speculation and partly because chromosomin proved very refractory to handle, it disappeared into the limbo of half-forgotten things for a quarter of a century (during which time the histones were studied intensively) but re-emerged about 10 years ago, renamed the non-histone or acidic chromosomal proteins, as a result of experiments which suggested that they, and not histones, might contain regulatory elements.

These proteins are complex. Upwards of 50 individual peptides (not all of which are strictly acidic) can be demonstrated and many, perhaps most, are probably not involved in regulation. Like a gold strike, this area is, therefore, full of promise, challenge and excitement; but for every worthwhile discovery, there are many disappointments. Monographs on the subject, for this reason, have been slow to appear and this is one of the first to be devoted entirely to the acidic proteins of the nucleus. It is, therefore, of special timeliness and interest.

It has 10 contributions. Vincent Allfrey first discusses control in prokaryotic and eukaryotic systems, drawing analogies between them; he also outlines preliminary experiments on the isolation of specific DNA-binding proteins. Gordhan Patel then presents a detailed review of methods for the isolation and fractionation of acidic proteins, which is followed by an account by LeSturgeon and Wray of their work with phenol-soluble acidic proteins. The fourth chapter, by Lewis Kleinsmith, discusses modification by phosphorylation and the possible role of this in modulating nuclear function. Chapters 5 by Bruce McGunn and 6 by LeSturgeon, Totten and Forer are concerned mainly with the nucleoproteins of Physarum polycephalum. Chapter 7 , by Berendes and Helmsing deals with the non-histone proteins of Dipteran polytene nuclei and is of particular interest since it brings together some biochemical findings and the morphological evidence about gene activity. The chapter, by the editors themselves reviews changes which have been reported in acidic proteins during cell growth. Tom Spelsberg devotes a chapter to a consideration of the role of nuclear acidic proteins in binding steroid hormones and, finally, Stewart Gilmour reviews the evidence that acidic proteins are involved in gene regulation in eukaryotes and discusses some of the models which have been proposed.

It is inevitable that any contemporary account of this field should be diffuse but gene regulation in eukaryotes is one of the greatest remaining challenges to the biologist and the acidic proteins of the cell nucleus are clearly implicated in it. The editors (Ivan Cameron and James Jeter) have managed to obtain contributions from several of the most experienced people in the field and the volume provides a reasonably comprehensive, up-to-date summary. It can, therefore, be recommended to laboratories in which work of this kind is being undertaken or contemplated.

John Paul 